\title{
Zygomatic Anterior Temporal Approach for High-position Upper Basilar Aneurysm
}

\author{
Makoto KATSUNO ${ }^{1}$ and Rokuya TANIKAWA ${ }^{2}$ \\ ${ }^{1}$ Department of Neurosurgery, Shonan Tobu Hospital, Chigasaki, Kanagawa, Japan; \\ ${ }^{2}$ Department of Neurosurgery, Teishinkai Hospital, Sapporo, Hokkaido, Japan
}

\begin{abstract}
Skull base techniques have often required high-position upper basilar aneurysm surgery based on a surgical corridor. Examples are the orbitozygomatic osteotomy for the trans-sylvian approach and zygomatic osteotomy for the subtemporal approach. However, clarity remains to be archived for the additional technique of the anterior temporal approach, including the middle surgical corridor of the trans-sylvian approach and subtemporal approach. In the present study, we describe the methodology and the problems associated with the zygomatic anterior temporal approach for high-position upper basilar artery aneurysms. Between 2007 and 2018, a total of 14 consecutive patients were received the same procedures of the zygomatic anterior temporal approach for high-position upper basilar aneurysms. Additionally, four patients underwent additional techniques to acquire further wide retro-carotid space. Complete ligation of all aneurysms was archived through the wide retro-carotid space in the absence of major surgical complications. Using the zygomatic anterior temporal approach, it is possible to both acquire a wide retro-carotid space and perform safety clip ligation of high-position upper basilar aneurysms without orbiotomy. However, additional orbiotomy should be taken into consideration by the surgeons if the orbital rim or internal carotid artery interferes with the surgical instruments or procedures.
\end{abstract}

Key words: surgery, basilar artery, anterior temporal approach, zygomatic osteotomy

\section{Introduction}

To data, surgical treatment of upper basilar aneurysms is accomplished by endovascular techniques, thanks to the progress in medical instrumentation. However, there have been inconsistent results in endovascular surgery for wide neck or large terminal basilar tip aneurysms are unstable. ${ }^{1-3)}$ As a consequence, to date, direct surgery remains the approach of choice for the treatment of these upper basilar aneurysms. There have been reports describing the advantages of the anterior temporal approach for upper basilar aneurysms., ${ }^{45}$ However, to archive safety and effectively perform high-position aneurysm surgery, some skull base techniques are required. Such additional techniques depend on the surgical corridor. Examples are orbitozygomatic osteotomy for the trans-sylvian approach ${ }^{6-8)}$ and zygomatic osteotomy for the subtemporal approach. ${ }^{9)}$ However, clarity remains to be archived for the requirement

Received May 7, 2019; Accepted August 13, 2019

Copyright $\odot 2019$ by The Japan Neurosurgical Society This work is licensed under a Creative Commons AttributionNonCommercial-NoDerivatives International License. of orbiotomy for the anterior temporal approach, which includes the middle surgical corridor of the transsylvian approach and the subtemporal approach. In the present study, we describe the methodology and problems related to achieving a certain clipping for high-position upper basilar aneurysms by means of the zygomatic anterior temporal approach without orbiotomy.

\section{Materials and Methods}

Between 2009 and 2018, a total of 14 patients were diagnosed with high-position upper basilar aneurysms. Diagnosis was performed using computed tomography (CT) and CT angiography (CTA). The heights of the aneurysms were measured from the inter-clinoid line at the apices of the anterior and posterior clinoid processes (Fig. 1). High-position aneurysms were defined as distal necks located $\geqq 10 \mathrm{~mm}$ from the inter-clinoid line. Aneurysmal clipping by the zygomatic anterior temporal approach was performed on all patients. The patients were monitored for any adverse events. Specifically, development of postoperative complications, CTA and magnetic resonance imaging were evaluated. 


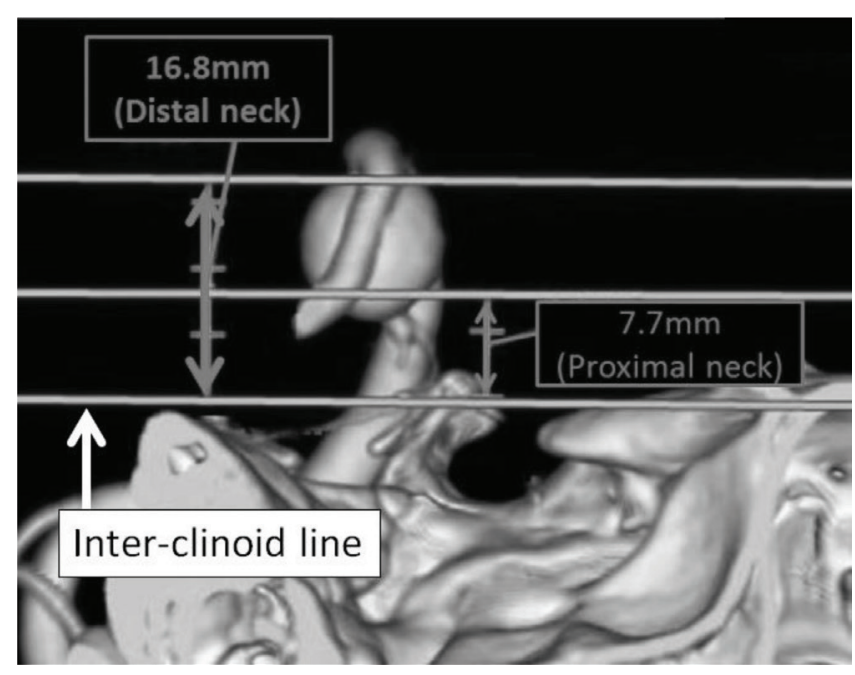

Fig. 1 The heights of the aneurysms were measured from the inter-clinoid line at the apices of the anterior and posterior clinoid processes. The distal neck of basilar artery superior cerebellar artery bifurcation aneurysm was located $16.8 \mathrm{~mm}$ above the inter-clinoid line.

\section{Surgical strategy}

The patients were placed in the supine position. Their heads were rotated approximately $30^{\circ}$ and fixed vertex down. Such position was chosen to obtain a posterior retraction of the temporal lobe and acquired to look up the operative view for high-position aneurysms. First, the skin flap was generated. Then, the temporal fascia was elevated to preserve the zygomatic branches of the facial nerve until exposing the zygomatic bone. The following steps described the zygomatic osteotomy procedure. First, the anterior margin of the zygomatic osteotomy was made parallel to the orbital rim, stating from the fronto-zygomatic suture that included the marginal zygomatic process. To preserve the zygomaticofacial nerve, a longitudinal incision was made behind the zygomaticofacial foramen (Fig. 2). The aim of this initial step is to contribute to the development of the inferolateral surgical corridor. Next, the posterior margin was made the root of the temporal zygomatic process while preserving the temporomandibular joint (Fig. 2). Finally, the zygomatic bone was removed from the masseter muscle. Following standard frontotemporal craniotomy, the temporal muscle reflected inferiorly. Drilling of the lateral orbital wall and the lesser wing of the sphenoid bone was performed until exposing the periorbita and opening the superior orbital fissure (Fig. 3). By means of these drilling procedures, a wider inferolateral operative filed was obtained. Subsequently, the anterior temporal approach was performed as previously described. ${ }^{2)}$ The anterior temporal approach allowed acquiring

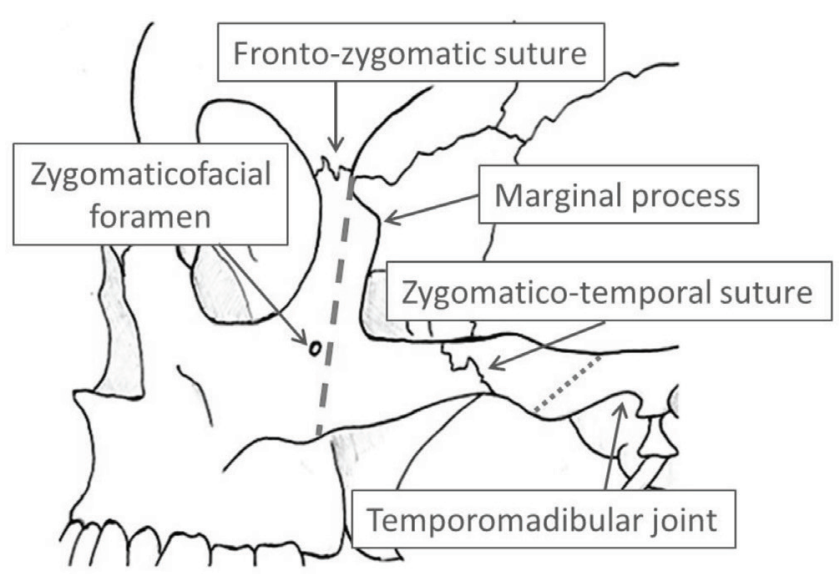

Fig. 2 Left-side zygomatic osteotomy. The anterior margin (long dotted line) is made of the fronto-zygomatic suture. The latter included a marginal process and passed behind the zygomaticofacial foramen. The posterior margin (short dotted line) is made by the temporal zygomatic process root, while paying attention to the temporomandibular joint.

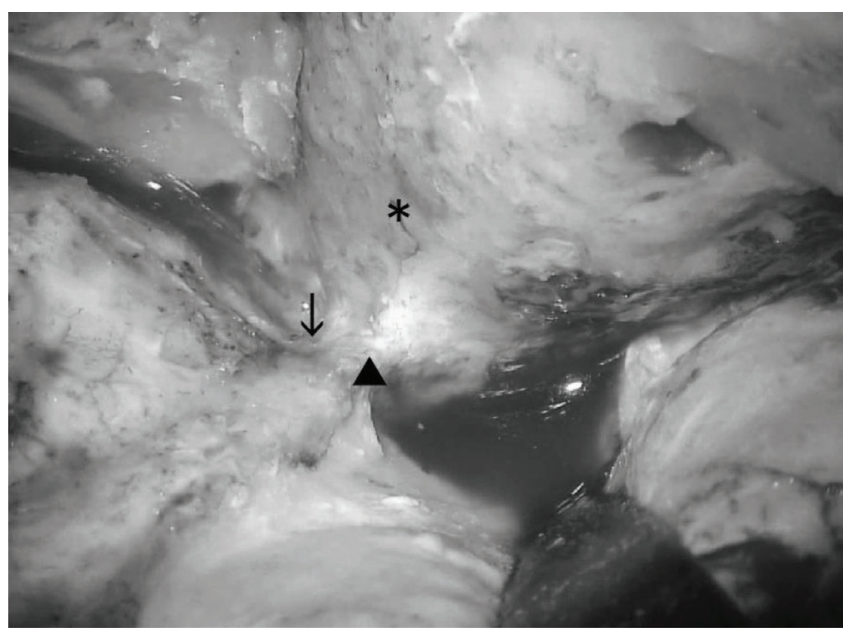

Fig. 3 Left side after drilling. Drilling of the lateral orbital wall and the lesser wing of the sphenoid bone was performed until exposing the periorbital $\left({ }^{*}\right)$ and meningo-orbital band (arrowhead) and opening the superior orbital fissure (arrow).

a wider retro-carotid space. Specifically, this was obtained by posteriorly retracting the temporal lobe without sacrificing any vessels. The posterior retraction of the temporal lobe created a wider lateral surgical corridor compared with the standard transsylvian approach. If necessary, to acquire an additional retro-carotid space, cutting of the distal dural ring under anterior clinoidectomy and severing of posterior communicating artery were additionally performed. Subsequently, clipping of the aneurysms was attempted under proximal control through the wide retro-carotid space. 


\section{Results}

Between 2007 and 2018, a total of 42 patients underwent the anterior temporal approach for upper basilar aneurysms. In 14 patients (Table 1), the height of the aneurysmal neck was diagnosed to be in a high position. Of note, the highest was located $17.2 \mathrm{~mm}$ above the inter-clinoid line. In eight patients, aneurysms were located at the basilar artery superior cerebellar artery (BA SCA) bifurcations, whereas in six patients, they were located at the BA tips. We observed subarachnoid hemorrhage (SAH) due to ruptured aneurysms in three patients. Additionally, three patients developed oculomotor nerve palsy due to aneurysmal compression. All remaining patients were asymptomatic. All patients received the zygomatic anterior temporal approach. The surgical techniques additionally included cutting of the distal dural ring under anterior clinoidectomy in three patients and severing of posterior communicating artery in one patient. For all aneurysms, complete neck clipping through the retro-carotid space under proximal control was performed. In four patients, we observed postoperative oculomotor nerve palsy. The latter was resolved within 6 months in only one patient. The remaining three patients demonstrated preoperative oculomotor palsy and did not improve after operation. Cerebral infarctions following surgical manipulation were observed in two patients. One of the two patients was due to excessive retraction of the middle cerebral artery at the basal ganglia. The other was determined by clip manipulation at the thalamus. The modified Rankin Scale score in the six postoperative months was 0 in seven patients, 1 in four patients, 3 in one patient and 4 and 5 due to initial SAH damage in one patient.

\section{Case illustration}

Case 3: A 61-year-old woman was diagnosed with a right BA SCA aneurysm that caused right oculomotor nerve palsy due to aneurysmal compression (Fig. 4A). The size of aneurysm was $10.8 \mathrm{~mm}$. It was located $16.8 \mathrm{~mm}$ above the inter-clinoid line (Fig. 1). The patient underwent surgery. Specifically, the zygomatic anterior temporal approach with cutting of the distal dural ring under anterior clinoidectomy was used (Fig. 4B). The aneurysm was ligated using two clips through the wide retro-carotid space. Despite the absence of any aneurysm on postoperative CTA (Fig. 4C), permanent oculomotor nerve palsy remained.

\section{Discussion}

Thus far, upper basilar aneurysms have been surgically treated by either the transsylvian ${ }^{10)}$ or the

Table 1 Clinical data summary for the 14 patients who underwent surgery with the zygomatic anterior temporal approach

\begin{tabular}{|c|c|c|c|c|c|c|c|c|c|}
\hline No. & $\begin{array}{l}\text { Sex/ } \\
\text { Age }\end{array}$ & $\begin{array}{l}\text { Symptom } \\
\text { (WFNS grade) }\end{array}$ & $\begin{array}{l}\text { Aneurysm } \\
\text { site }\end{array}$ & $\begin{array}{l}\text { Aneurysm } \\
\text { size }(\mathrm{mm})\end{array}$ & $\begin{array}{l}\text { Inter-clinoid } \\
\text { line (mm) }\end{array}$ & $\begin{array}{l}\text { Additional } \\
\text { techniques }\end{array}$ & $\begin{array}{l}\text { Clip } \\
\text { insertion } \\
\text { space }\end{array}$ & $\begin{array}{l}\text { Surgical } \\
\text { complications }\end{array}$ & $\mathrm{mRS}$ \\
\hline 1 & $\mathrm{~F} / 69$ & \multirow[t]{2}{*}{ ON palsy } & Lt BA-SCA & 16.6 & 17.2 & & Lt RC & ON palsy & 1 \\
\hline 2 & $\mathrm{M} / 48$ & & Rt BA-SCA & 4.8 & 12.0 & & Rt RC & ON palsy (Transit) & 1 \\
\hline 3 & $\mathrm{~F} / 61$ & \multirow[t]{5}{*}{ ON palsy } & Rt BA-SCA & 10.8 & 16.8 & $\mathrm{AC}$ & Rt RC & ON palsy & 1 \\
\hline 4 & $\mathrm{~F} / 73$ & & Lt BA-SCA & 5.9 & 12.2 & - & Lt RC & CI (Basal ganglia) & 1 \\
\hline 5 & $\mathrm{M} / 75$ & & Rt BA-SCA & 6.2 & 15.0 & - & Rt RC & - & 0 \\
\hline 6 & $\mathrm{~F} / 65$ & & $\mathrm{BA}$ & 11.0 & 12.8 & AC \& Pcom & Rt RC & - & 0 \\
\hline 7 & $\mathrm{~F} / 66$ & & Lt BA-SCA & 4.2 & 13.6 & - & Lt RC & - & 0 \\
\hline 8 & $\mathrm{~F} / 73$ & \multirow[t]{4}{*}{ SAH (grade 5) } & $\mathrm{BA}$ & 3.0 & 13.0 & - & Rt RC & - & 4 \\
\hline 9 & $\mathrm{~F} / 72$ & & $\mathrm{BA}$ & 4.1 & 12.0 & - & Rt RC & - & 0 \\
\hline 10 & F58 & & $\mathrm{BA}$ & 9.8 & 10.1 & - & Rt RC & - & 0 \\
\hline 11 & $\mathrm{~F} / 49$ & & $\mathrm{BA}$ & 4.0 & 11.5 & - & Rt RC & - & 0 \\
\hline 12 & $\mathrm{~F} / 76$ & \multirow[t]{2}{*}{ SAH (grade 2) } & $\mathrm{BA}$ & 8.7 & 10.0 & - & Rt RC & CI (Thalamus) & 3 \\
\hline 13 & $\mathrm{M} / 60$ & & Rt BA-SCA & 3.0 & 12.2 & - & Rt RC & - & 0 \\
\hline \multirow[t]{2}{*}{14} & $\mathrm{M} / 73$ & SAH (grade 5) & Lt BA-SCA & 12.5 & 10.0 & $\mathrm{AC}$ & Lt RC & ON palsy & 5 \\
\hline & & ON palsy & & & & & & & \\
\hline
\end{tabular}

AC: anterior clinoidectomy, BA: basilar artery, CI: cerebral infarction, F: female, Lt: left, M: male, mRS: modified Rankin Scale, ON palsy: oculomotor nerve palsy, Pcom: severing of posterior communicating artery, RC: retro-carotid space, Rt: right, SAH: subarachnoid hemorrhage, SCA: superior cerebellar artery, WFNS: World Federation of Neurological Surgeons. 

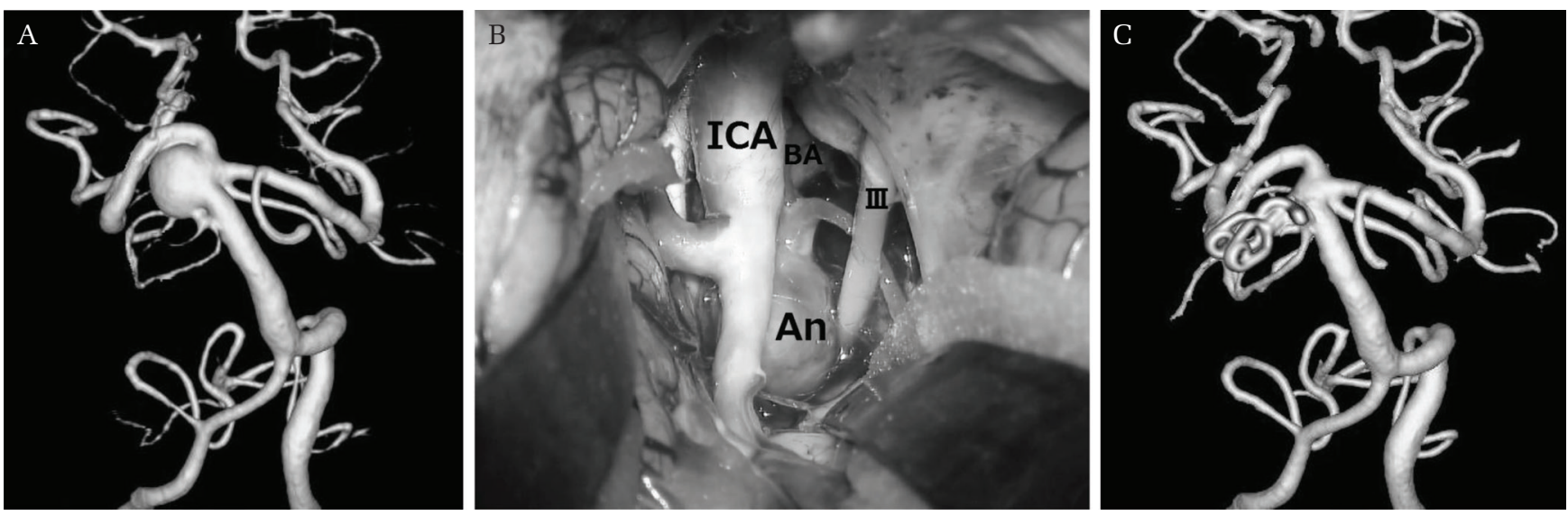

Fig. 4 Pre and postoperative computed tomography angiography (CTA) and intra-operative photograph of Case 3. (A) On preoperative CTA, we observed a saccular aneurysm at the bifurcation of the right basilar artery-superior cerebellar artery. (B) The zygomatic anterior temporal approach with anterior clinoidectomy exposed the aneurysm through the wide retro-carotid space. (C) The aneurysm disappeared on postoperative CTA. BA: basilar artery, ICA: internal carotid artery.

subtemporal approach. ${ }^{11,12)}$ It has been extensively shown that each approach has some advantages and disadvantages in terms of the surgical corridor. The transsylvian approach is difficult to confirm the anatomical structures behind the upper basilar aneurysms. On the contrary, the subtemporal approach allows for good visualization for behind the upper basilar aneurysms but has disadvantage for the protection from the retraction of temporal lobe. The anterior temporal approach is a modification of the transsylvian approach to acquire the middle surgical corridor of the transsylvian and subtemporal approaches..5) Furthermore, this would allow for making up for the deficiency of the disadvantages both in the transsylvian and in the subtemporal approaches. This approach allows acquiring a wider retro-carotid space by gentle posterior retraction of the temporal lobe, when compared with the subtemporal approach, brought about an additional lateral surgical corridor compared with the standard transsylvian approach. The acquisition of wider retro-carotid space is an important point for upper basilar aneurysm surgeries. Specifically, this is due to the fact that such space is achieved by the lateral surgical corridor for the upper basilar complex. Furthermore, it is possible to preserve the perforators from the basilar tip during clipping. Therefore, many clipping procedures of the upper basilar aneurysms have been performed through the retro-carotid space. ${ }^{13)}$

Some techniques need to be supplemented for the treatment of high-position upper basilar aneurysms to acquire the look up operative field. For these aneurysms, transsylvian approaches with orbitozygomatic osteotomy are often performed. ${ }^{6-8)}$ On the contrary, anterior temporal approach is not always necessary the orbiotomy from the difference of surgical corridor. However, the operative field remains insufficient by exclusively zygomatic osteotomy. Therefore, for the zygomatic anterior temporal approach, additional drilling of the lateral orbital wall and the lesser wing of the sphenoid bone is required. The requirement for this drilling is different from the zygomatic subtemporal approach.9) Through this procedure, to acquire a sufficient operative field in the retro-carotid space, orbiotomy becomes unnecessary. Yet, orbiotomy is required in two cases for aneurysmal clips. The first is related to the side of the approach. When the clip forceps are inserted opposite to the approach side, the orbital rim interferes with the inferior insertion of the clip forceps at shallow spaces (Fig. 5). The other is related to the tilt of the intracranial internal carotid artery (ICA). When the ICA remarkably leans following atherosclerotic changes, the retro-carotid space narrows down and the optico-carotid space widens. Under such condition, there is a need to change the clip's insertion space to the optico-carotid space. Therefore, the surgical corridor also changes from inferolateral to infero-frontal.

Although the presented zygomatic anterior temporal approaches were used to perform complete neck clippings without the temporal lobe contusion, some cases in our series presented postoperative oculomotor nerve palsy and cerebral infarction. First, the potential causes of oculomotor nerve palsy include long-term aneurysmal compression and surgical manipulations. Therefore, surgeons should monitor stress to the oculomotor nerve 

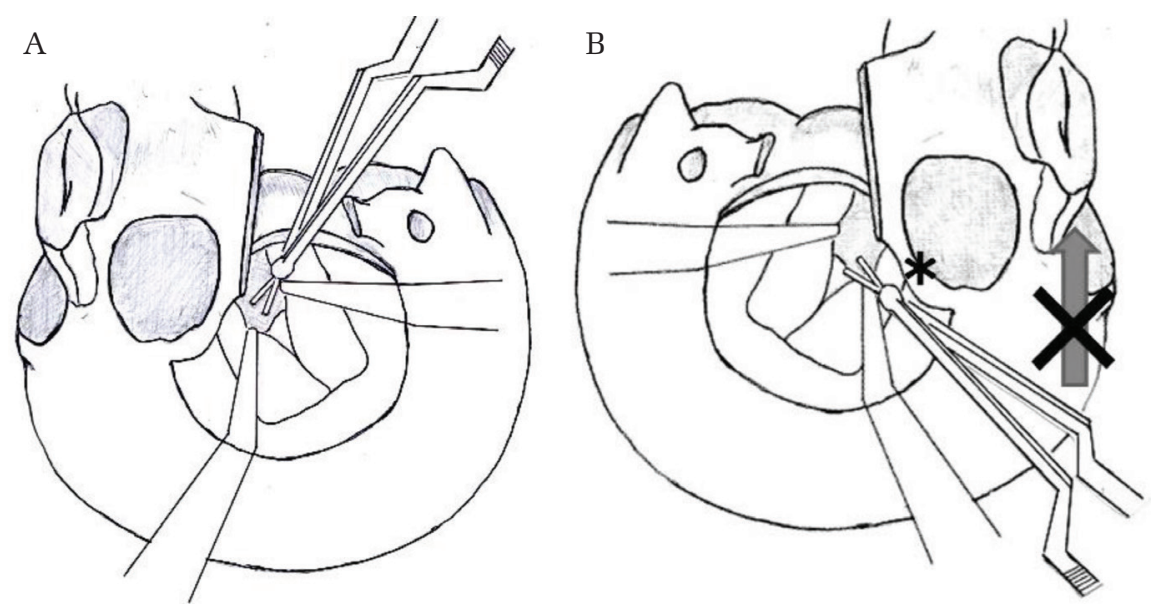

Fig. 5 Crosswise difference of interference by the orbital rim ( ${ }^{*}$ ). (A) It was possible to perform an inferior insertion of clip forceps from the right side without interference through the orbital rim. (B) The flexibility of the clip forceps from the right side was limited by the orbital rim and the insertion angle of the clip forceps was changed to lateral.

Table 2 Characteristics of various approaches for high position upper basilar aneurysm

\begin{tabular}{|c|c|c|c|c|c|c|c|}
\hline Approach & $\begin{array}{l}\text { Operative } \\
\text { field }\end{array}$ & $\begin{array}{c}\text { Retraction } \\
\text { for brain }\end{array}$ & $\begin{array}{l}\text { Retraction } \\
\text { for ICA }\end{array}$ & $\begin{array}{l}\text { Retraction } \\
\text { for ON }\end{array}$ & $\begin{array}{l}\text { Confirmation } \\
\text { of behind } \\
\text { aneurysm }\end{array}$ & $\begin{array}{c}\text { Confirmation } \\
\text { of contralateral } \\
\text { structures }\end{array}$ & $\begin{array}{c}\text { Combined } \\
\text { with various } \\
\text { techniques }\end{array}$ \\
\hline Z-ATA & Wide & + & + & + & + & + & ++ \\
\hline OZ-TSA & Narrow & + & ++ & - & - & + & ++ \\
\hline Z-STA & Wide & ++ & - & + & ++ & - & + \\
\hline TTVA & $\begin{array}{l}\text { Narrow and } \\
\text { deep }\end{array}$ & - & - & - & - & ++ & - \\
\hline
\end{tabular}

-: none or impossible, +: mild or not impossible, ++: severe or possible, ATA: anterior temporal approach, ICA: internal carotid artery, ON: oculomotor nerve, OZ: orbitozygomatic, STA: subtemporal approach, TSA: transsylvian approach, TTVA: transthird ventricular approach, Z: zygomatic.

during the zygomatic anterior temporal approach and should open the porus oculomotorius to acquire oculomotor nerve mobility if necessary. Next, it is impossible to confirm structures behind aneurysm for posterior projection basilar tip aneurysm even if the zygomatic anterior temporal approach is used. The thalamic infarction case described in this report demonstrated a posterior projection basilar tip aneurysm; insufficient confirmation resulted in thalamoperforater damage due to clip manipulation. The zygomatic subtemporal approach is, therefore, more suitable than the zygomatic anterior temporal approach for the management of a posterior projection aneurysm.

Endovascular surgery is becoming the first choice for the management of the upper basilar artery aneurysm on the basis of the development of instrument used in the procedure; good results are frequently obtained. ${ }^{14)}$ However, it has some disadvantages, such as coil compaction after surgical management of large basilar tip aneurysm, ${ }^{3)}$ as well as the need for coil replacement for wide-neck or thrombosed aneurysms. ${ }^{1,2}$ Therefore, a safer and more secure direct surgery approach is required for refractory upper basilar aneurysms by endovascular surgery.
Notably, when the operative field is insufficient based on the procedures described above, alternative surgical strategies should be considered by surgeons in accordance with the characteristics of each approach. Examples of standard alternative surgical strategies include the orbitozygomatic transsylvian approach, zygomatic subtemporal approach, and the trans-third ventricular approach ${ }^{15)}$ (Table 2).

\section{Limitation}

This study had some limitations as follows: small numbers, mid-term follow-up, and no randomization.

\section{Conclusion}

In conclusion, using the zygomatic anterior temporal approach, it is possible to acquire a wide retro-carotid space and perform safety clip ligation of high-position upper basilar aneurysms without orbiotomy. However, surgeons should consider additionally performing an orbiotomy if the orbital rim or ICA interferes with the surgical instruments or procedures.

\section{Conflicts of Interest Disclosure}

None. 


\section{References}

1) Chow MM, Woo HH, Masaryk TJ, Rasmussen PA: A novel endovascular treatment of a wide-necked basilar apex aneurysm by using a Y-configuration, double-stent technique. AJNR Am J Neuroradiol 25: 509-512, 2004

2) Spiotta AM, Gupta R, Fiorella D, et al.: Mild-term results of endovascular coiling of wide-necked aneurysms using double stents in a Y configuration. Neurosurgery 69: 421-429, 2011

3) Peluso JP, van Rooij WJ, Sluzewski M, Beute GN: Coiling of basilar tip aneurysms: results in 154 consecutive patients with emphasis on recurrent haemorrhage and re-treatment during mid- and long-term follow-up. $J$ Neurol Neurosurg Psychiatry 79: 706-711, 2008

4) Heros RC, Lee SH: The combined pterional/anterior temporal approach for aneurysms of the upper basilar complex: technical report. Neurosurgery 33: 244-250; discussion 250-251, 1993

5) Katsuno M, Tanikawa R, Izumi N, Hashimoto $M$ : A modified anterior temporal approach for lowposition aneurysms of the upper basilar complex. Surg Neurol Int 6: 10, 2015

6) Gonzalez LF, Crawford NR, Horgan MA, Deshmukh P, Zabramski JM, Spetzler RF: Working area and angle of attack in three cranial base approaches: pterional, orbitozygomatic, and maxillary extension of the orbitozygomatic approach. Neurosurgery 50: 550-555; discussion 555-557, 2002

7) Hsu FP, Clatterbuck RE, Spetzler RF: Orbitozygomatic approach to basilar apex aneurysms. Neurosurgery 56: 172-177, 2005

8) Ikeda K, Yamashita J, Hashimoto M, Futami K: Orbitozygomatic temporopolar approach for a high basilar tip aneurysm associated with a short intracranial internal carotid artery: a new surgical approach. Neurosurgery 28: 105-110, 1991

9) Pitelli SD, Almeida GG, Nakagawa EJ, Marchese AJ, Cabral ND: Basilar aneurysm surgery: the subtemporal approach with section of the zygomatic arch. Neurosurgery 18: 125-128, 1986

10) Yasargil MG, Antic J, Laciga R, Jain KK, Hodosh RM, Smith RD: Microsurgical pterional approach to aneurysms of the basilar bifurcation. Surg Neurol 6: 83-91, 1976

11) Drake CG: The treatment of aneurysms of the posterior circulation. Clin Neurosurg 26: 96-144, 1979

12) Hernesniemi J, Ishii K, Niemelä M, Kivipelto L, Fujiki M, Shen H: Subtemporal approach to basilar bifurcation aneurysms: advanced technique and clinical experience. Acta Neurochir Suppl 94: 31-38, 2005

13) Tanaka Y, Kobayashi S, Sugita K, Gibo H, Kyoshima K, Nagasaki T: Characteristics of pterional routes to basilar bifurcation aneurysm. Neurosurgery 36: 533-538; discussion 538-540, 1995

14) Bavinzski G, Killer M, Gruber A, Reinprecht A, Gross CE, Richling B: Treatment of basilar artery bifurcation aneurysms by using Guglielmi detachable coils: a 6-year experience. J Neurosurg 90: 843-852, 1999

15) Canbolat A, Onal C, Kiriş T: A high-position basilar top aneurysm approached via third ventricle: case report. Surg Neurol 39: 196-199, 1993

Address reprint requests to: Makoto Katsuno, MD, Department of Neurosurgery, Shonan Tobu Hospital, 500 Nishikubo, Chigasaki, Kanagawa 253-0083, Japan. e-mail: mkatsuno@nms.ac.jp 